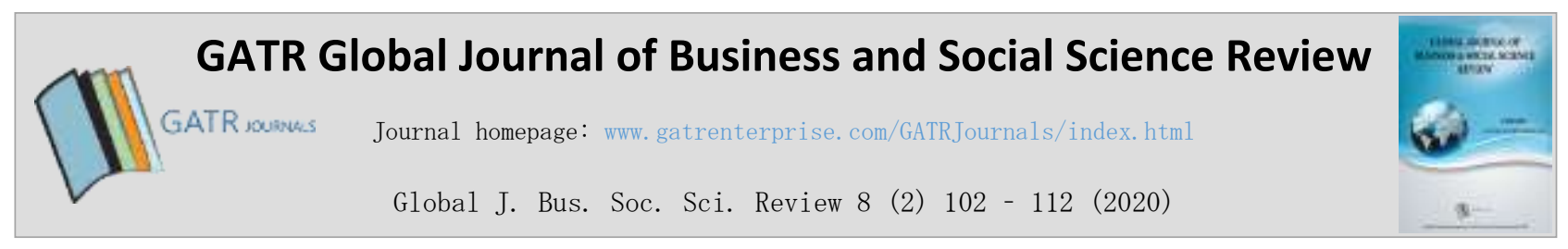

\title{
Empowering Surabaya Creative Communities and Start-Ups through Human-Centered Design
}

\author{
Diana Thamrin $^{1 *}$, Laksmi Kusuma Wardani², Ronald Hasudungan Irianto Sitindjak ${ }^{3}$ \\ ${ }^{1,2,3}$ Interior Design Department, Petra Christian University, Siwalankerto 142-144, Surabaya 60236, Indonesia
}

\begin{abstract}
Objective - Creative communities have the potential to increase a city's social, economic, and touristic values. Despite their evident existence in Surabaya, these communities lack support in terms of public spaces and exhibition facilities with suitable designs that could accommodate their unique activities and communicate their aspirations to the public. This research-design project aims to prove the social and economic benefits of the human-centered design process by implementing various human-centered design approaches in the interior design of creative community spaces (CCS) so that they can accommodate the unique activities of existing creative communities and serve as assembly points for entrepreneurial or start-up groups.

Methodology/Technique - Two teams of interior designers were tasked to design a community space and exhibition facility for two creative communities in Surabaya. A combined method based on different human-centered design approaches of applied ethnography, participatory design, co-design, contextual design, emphatic design, and lead user approach was conducted through six stages of design process consisting of: Empathize, Point of View, Define, Ideate, Prototype, and Test.

Findings \& Novelty - The results of this research-design project are novel designs of community co-working spaces and exhibition facilities based on the unique human values, hobbies, and characteristics of the creative community that proved the social and economic benefits of human-centered design in the practice of interior design. Through the design of the creative community spaces yielded, interior and building designers can promote the activities and aspirations of existing creative communities such that they may, in turn, contribute to the development of Surabaya's social, economic, and touristic values.
\end{abstract}

Type of Paper: Review

JEL Classification: M13, M19.

Keywords: Human-Centered Design; Creative Community; Community Design; Surabaya; Creative Economy; Design.

Reference to this paper should be made as follows: Thamrin, D; Wardani, L.K; Sitindjak, R.H.I. (2020). Empowering Surabaya Creative Communities and Start-ups through Human-centred Design, Global J. Bus. Soc. Sci. Review, 8(2): 102 - 112. https://doi.org/10.35609/gjbssr.2020.8.2(4)

\section{Introduction}

Creative communities have the potential to increase a city's social, economic and touristic values. Recent studies in Indonesia have acknowledged the role of young creative communities in developing the creative

\footnotetext{
${ }^{*}$ Paper Info: Revised: March 11, 2020

Accepted: June 3, 2020

* Corresponding author: Diana Thamrin

E-mail: dianath@petra.ac.id

Affiliation: Interior Design Department, Petra Christian University, Surabaya, Indonesia
} 
economy. They can encourage the society to be productive, activate the spirit of young entrepreneurship to build creative businesses that relate with their hobbies and character, as well as foster social sensitivity in teamwork with others to succeed together (Marzaman, 2018). Despite the existence of active creative communities in Surabaya, these communities lack spaces that can fully accommodate their various activities. They often rely on conventional leased spaces, living rooms or garages of their own homes with unattractive storage spaces for their works of art and collections. They also lack the medium to promote their aspirations and works to the wider community. To design facilities that correspond to their distinct human talents, character and aspirations that are also contained in their artworks require a deeply humanistic approach in the design process as they cannot be addressed by conventional working or exhibition spaces.

This research-design project aims to prove the social and economic benefits of human-centered design in the interior design of community spaces. It starts with discussing the potential of creative community spaces in strengthening a city's social, economic and touristic value and explores the methods and benefits of human-centered design in the practice of human-centered design. The paper further tests the hypothesis by implementing the various theoretical approaches of human-centered design in the interior design of creative community spaces (CCS) and their exhibition facilities to accommodate the unique activities of existing creative communities and design them to serve as assembly points for entrepreneurial or start-up groups. Two teams of interior designers were assigned to design a community co-working space and exhibition facility for two existing art communities, by applying human-centered design approaches defined by Steen (2007). Through the human-centered design of CCS yielded, it is hoped that interior designers can help promote the activities and aspirations of existing creative communities so that their existence may contribute to the development of Surabaya's social, economic and touristic values.

\section{Literature Review and Hypothesis}

\subsection{The Role of Creative Communities and Spaces in the Creative Economy}

Recent studies in Indonesia have claimed that young creative communities can have a positive impact on local economies (Hidayat, 2017 \& Dewi, 2016). When they create new businesses and work across industries, they trigger economic growth and employment. Generally, entrepreneurs are attracted to cities with available resources and connections, especially in terms of access to knowledge and specific needs. Such environments can be facilitated and managed by creative community spaces (CCSs), which are a number of physical spaces that promote creativity, serving as an assembly point for entrepreneurial and startup groups (Dewi, 2016; Mulas, 2017). The aesthetic and functional contextualization of a place is a productive factor in comprehending innovation and creativity (Duxbury et. al., 2010). These spaces should provide facilities and services for activities from meetings, discussions, meetings to an organization to skills training, and global opportunities. They also facilitate collaboration between communities and function as mediums of communication, network expansion, and appreciation to the community or people who have worked and innovated (Dewi, 2016). In Indonesia, 96.61\% of creative communities still do not have their own business units (Maulana, 2020). This is mainly due to a lack of support in terms of spaces and facilities that can accommodate their activities and promote them to the public. Hence, architects and interior designers of CCS play a vital role in empowering creative communities through their contribution to the design of CCSs. Apart from their contribution to a city's economic development, creative communities, especially those that uphold one's regional potentials or culture also play an important role in tourism. Community participation in tourism helps to maintain and promote the community and city's local culture, traditions, and regional knowledge (Aref, 2011). Hence, the success of a city's tourism not only depends on its historic or physical artifacts but also on the contribution of its local community and how they help in creating interactive memories for visitors. This is especially relevant for Surabaya city that is truly known in Indonesia for the characteristics of its open, daring, dominating, egalitarian, blunt and dynamic people, locally termed as arek Suroboyo (Tinarso et. al., 2018). It's these human values that are essential to be

Global J. Bus. Soc. Sci. Review 8 (2) $102-112$ (2020) 
explored and promoted as the identity of Surabaya. Therefore, the practice of human-centered design can enable a humanistic and phenomenological approach in the design of impactful creative community spaces in Surabaya.

\subsection{Empowering Creative Communities through Human-centered Design}

Human-centered design (HCD) is a problem-solving methodology widely used in development and management systems that create solutions to problems by incorporating human viewpoints at all levels of the problem-solving process (LUMA Institute, 2012). Human involvement usually occurs in situational analysis, brainstorming, conceptualizing, creating and implementing projects to engage constructively with end-users. Human-centered development builds on participatory action research by going beyond the participation of stakeholders and creating solutions to problems (Kang et. al., 2015). The initial stage typically revolves around participation or immersion, analysis, and contextual framing in which the innovator is absorbed in the problem and the culture. The effect phases can then be based on group brainstorming, modeling, and prototyping. Steen et. al. (2007) categorizes human-centered design into 6 different approaches. The first approach is Applied Ethnography, in which the purpose of this anthropologic approach is to understand the daily life of a group of people as a social phenomenon, by becoming part of their daily lives and living in their daily setting (Pelto, 2013).

The second HCD approach is Participatory Design, a design approach that invites all groups of people involved in the project (users, partners, communities, local residents and visitors) to contribute ideas throughout the design process. This is often done through focus group discussions (FGD). The third HCD approach is Contextual Design: an approach that uses ethnographic methods, with a structured and defined process that integrates concepts, products, and tests of user experience based on situational analysis of place and time. The fourth approach is the Lead-User Approach, an approach that looks at problems that are not yet common so that it can provide design solutions before the problem becomes a general case and hence grants higher opportunities for innovation (Brem et. al., 2018).

Next, the fifth HCD approach is Empathic Design, a design approach that provides design solutions by understanding the user's feelings towards an existing product (Lee, 2003). It can often create innovations in design and provide solutions to problems that are not yet known to the user. The last HCD approach is CoDesign: a design approach that evolved from the concept of Participatory design but only a few potential users are involved, such as experts who truly understand the design, so that the cooperation established is truly collaborative and structured. They are directly involved in the design process, hence not merely functioning as advisors (Zamenopoulos et. al., 2018). In the field of interior design, HDC has often been majorly adapted into Universal or Inclusive Design applications compared to its broad practice in the field of computer, software and other technology-based interactive design (El Sayad et. al., 2017).

This paper expands the practice of HCD in the field of interior design to address the cultural, economic and sociological aspects of spaces rather than solely on the functional aspect as has often been accomplished in Universal Design applications. The practice of human-centered design in the design of creative community spaces would bring out the distinct human values of the creative communities in Surabaya that can contribute to the development of the city's social, economic and touristic values. 


\section{Research-Design Methodology}

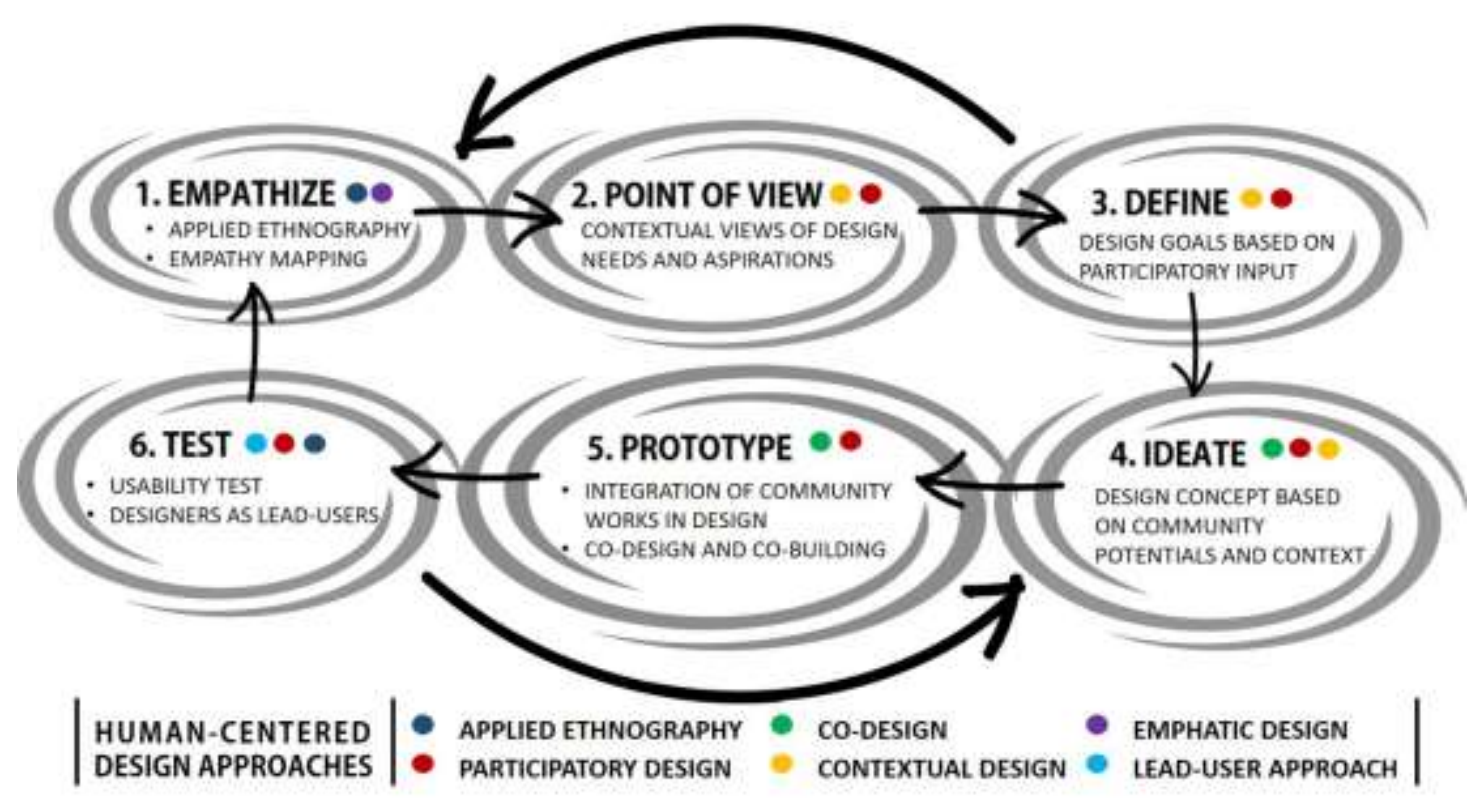

Figure 1. Implementing Human-centered Design (HCD) Approaches in the Design Process (Source: Author, 2019)

Two teams of interior designers were assigned to design a community co-working space and exhibition facility for two existing art communities. The communities taken as objects for this research-design project were chosen based on purposive sampling, in which they must meet two criteria. The first criterion is that the community must be active, having a routine activity, once a month at the least. The second criterion is that the community must have activities or works that can promote the cultural, economic and touristic value of Surabaya city.

The research-design methodology used was a combined method that applied different human-centered approaches defined by Steen (2007) that was conducted through 6 stages of design process adapted from LUMA Institute (2012) as shown in Figure 1. The first stage is the Empathize stage, in which designers perform ethnographic field survey and empathy mapping process of collecting community data by participating in the community's activities and daily setting. Next, in the Point of View stage, designers produce a contextual view of design needs and aspirations. This is then followed by the Define stage in which designers set design goals through the participatory and contextual design process. The design creation process then commences in the Ideate stage, in which designers brainstorm and formulate design concepts based on community contextual potentials and characteristics. Next, in the Prototype stage, designers plan and integrate community works in the design product and build it collaboratively with the community. Finally, in the Test stage, the designers test the results of the design by being lead-users of the product and evaluate its effectiveness with the community.

\section{Results and Discussion}

Two teams of designers were assigned to 2 active creative communities in Surabaya. The first community was the Love Suroboyo community that consists of photographers and journalists who are passionate about Surabaya city. Their works often sought to capture the potentials and news about Surabaya, from events, places, incidents, culture, history, and people. Some members of this community offer freelance photo or videography projects for wedding celebrations, promotions, events, etc. The second community was the Doodle Art Community, consisting of creative artists and illustrators who meet up regularly to share ideas,

Global J. Bus. Soc. Sci. Review 8 (2) $102-112$ (2020) 
hold public workshops and perform doodle art for leisure, art therapy, and educational purposes. They produce various doodle merchandise which they sell during markets and exhibition events. Both communities are strongly active communities that have the potentials to form startups in the creative economic wave and the skills that can contribute to the local identity and social as well as touristic development of Surabaya city.

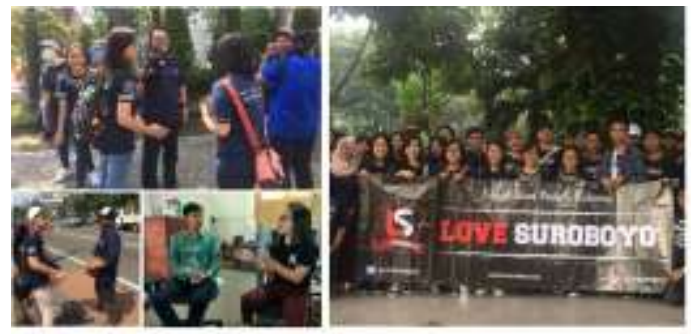

(a)

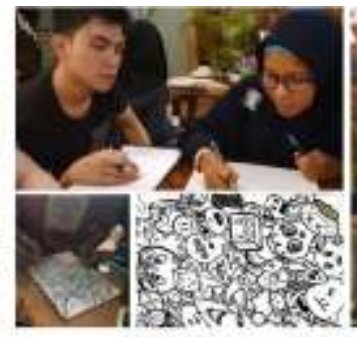

(b)

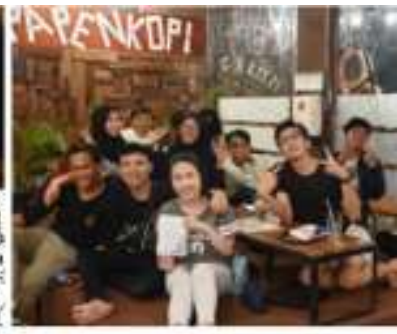

Figure 2. An emphatic and ethnographic field observation process was conducted through the participation of designers in the creative community's routine events and activities. (Source: Author, 2019)

In the first stage of design (Empathize), the two teams of designers participated in their assigned community's activities (Figure 2). The first team participated in the annual Blusukan activity, which is an exploring or visiting activity inspired by the new style of governance in Indonesia adopted by President Jokowi and other influential leaders, including the mayor of Surabaya, to fully understand the conditions of the people. The designers involved themselves in exploring activities, documenting, photographing, conversing with the locals that they met to catch the same feeling and aspirations of the community. Meanwhile, the second team participated in Doodle Art Surabaya's weekly gathering, learning and performing various sorts of doodle techniques together with the community. Hence, both teams immersed themselves in the community's situational context of place and time through ethnographic and emphatic approaches of observation. This helped them in gaining a deep understanding of the community's passion, the purpose of their existence, their strong desire in conveying the pride of their city and their artistic and daring expressions of freedom and creativity.

In the Point of View to Define stage, the designers sat together with the community and established a point of view of the needs of the community, defining the problems that needed to be solved through their design interventions. This was done through a focus group discussion that included several community members, a design mentor, and the design team, based on the immersive and contextual view that they had acquired from the Empathize stage (Figure 2). The designers then created design goals based on the participatory inputs of each member through affinity diagrams and concept mappings based on Pena's (2012) spatial programming aspects of function (people, activities, relationships), form (site, environment, quality), economy (initial budget, operating cost, revenue streams) and time (past, present, future). These goals were created based on the context of the community as journalists, photographers, and artists who all desired that their aspirations for Surabaya city, articulated in their photographic and artworks, could be seen, heard, felt and touched by the public through the design of their community centers and exhibition facilities. Hence, in this stage, the participants mapped out all of the community's potentials that should be the contents to be exposed through their design interventions. 


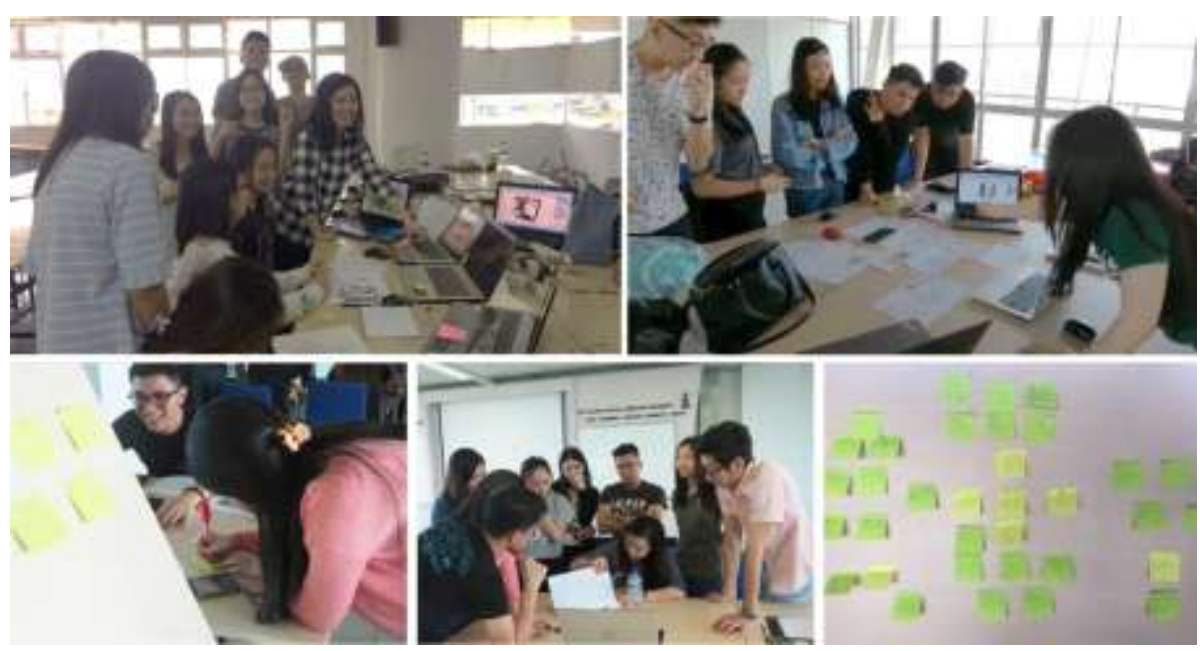

Figure 3. The contextual and participatory design process of defining design goals that are based on FGDs, affinity graphics and community input (Source: Author, 2019)

Entering the Ideate stage, the designers produced various concepts for the design of a community center for each community. They based their concepts on the community's character, aspirations, and content of exposition that they collaboratively acquired from the Define stage. For the Love Suroboyo Community, the goal was to create a community space that could highlight the icons and image of Surabaya city, often captured by their photographic and journalistic works. The conceptual design produced was based on Surabaya's famous Red Bridge (Figure 4a), a historical site of the huge battle that happened between the Indonesian army and the West after their struggle for independence, the event from which Surabaya gained the epithet as the "city of heroes." The community center was designed with high considerations to how journalists and photographers work together with photo studios and collaborative spaces that were fused with the walls, floors, and ceilings. They adopted patterns and images of Surabaya landmarks, such as the Suro (shark) and Boyo (crocodile), statue, symbolizing a fierce battle and the Bambu Runcing (sharp bamboo monument), the weapon that was used during the battle in Surabaya, both icons symbolizing the local slogan "dare to face threat" and solidarity of arek Suroboyo.

Hence, the community center can function as an exhibition space equipped with various photo spots that were integrated with the co-working spaces, a unique form of working space in the context of the community's aspirations for Surabaya. For the Doodle Art community, the designers based their concepts on the dynamic features of doodle art itself that were fused with icons of Surabaya city to differentiate from the doodle art communities in other areas. They integrated the community's doodle works into the furniture, walls, façade, ceilings, and floors that were used as means of wayfinding and defining the boundaries between public and private spaces (Figure $4 \mathrm{~b}$ ). Hence, both teams of designers managed to create a new interior design concept that would have potentially been undiscovered without the approach of contextual design and participatory involvement of the community in the design process. 


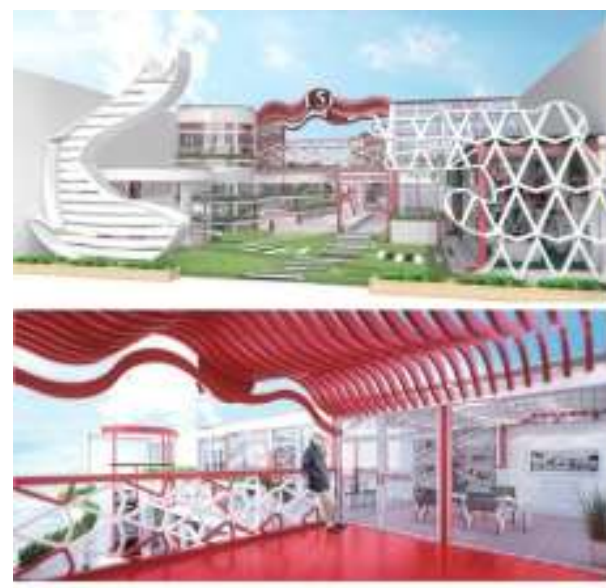

(a)

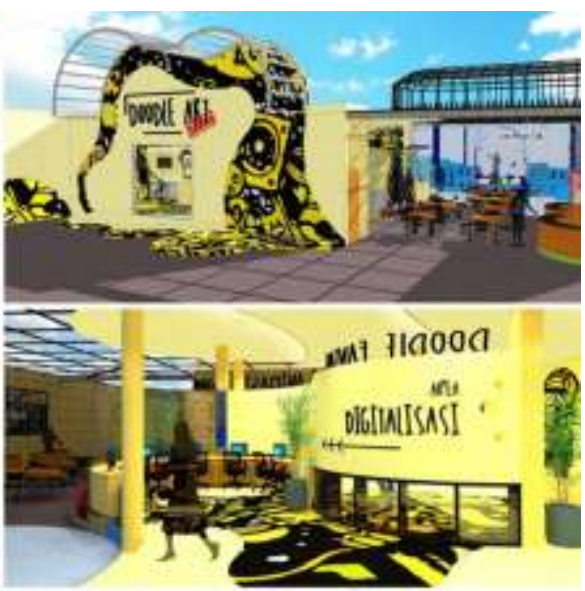

(b)

Figure 4. Conceptual renderings of creative community spaces for (a) Love Suroboyo Community (Designed by Favian Grady) and (b) Doodle Art Surabaya (Designed by Adi Kelvianto) based on Surabaya city icons and the daring and dynamic expression of arek Suroboyo (Source: Author, 2019).

Entering the Prototype stage, the designers actualize a part of the conceptual ideas from the Ideate stage, by building a set of exhibition facilities that can be used by the community during exhibition events in public spaces. Building the booth was done through a collaborative process of planning, finding materials, constructing, transporting and assembling (Figure 5).

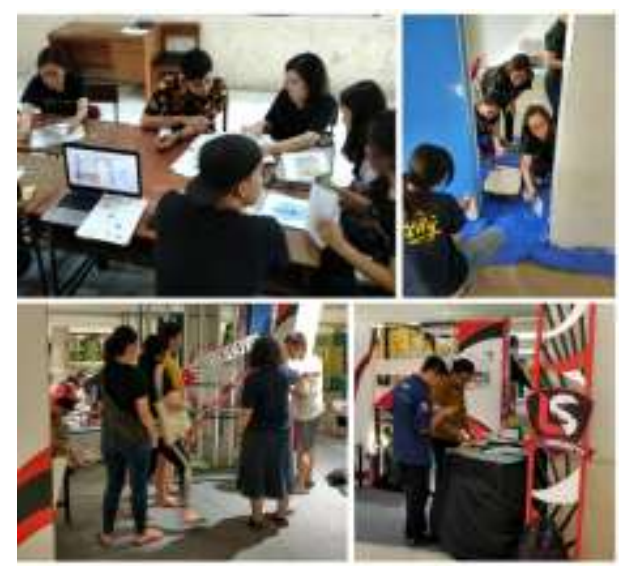

(a)

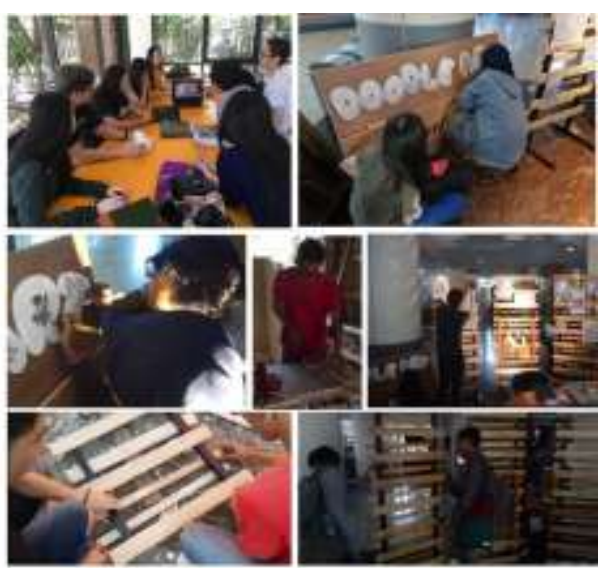

(b)

Figure 5. Participatory and co-design design process of planning, building, and setting of exhibition booth in malls and public halls for the (a) Love Suroboyo Community, (b) Doodle Art Surabaya Community (Source: Author, 2019).

For the Love Suroboyo community booth, the designers adopted the pattern of Suro and Boyo creatures (shark and crocodile) mentioned earlier into the display booth that consisted of a photo and journalistic article display area and display tools for their merchandise items such as clothes, mugs, and brochures (Figure 6a). For the Doodle Art Surabaya community (Figures $5 \mathrm{~b}$ and $6 \mathrm{~b}$ ), the designers built the display booth in which the community contributed their expertise in doodling and incorporated their doodle work in the display facility itself. The signage of their community name has been decorated with fresh works of their doodle art on spot. Hence, the exhibition booth was set up with the approach of co-design and co-building, ensuring its usability and desirable value to the community. Both prototypes enabled the creation of a new form of art that highlighted the creativity and boldness of the Surabaya people. They also provided a starting point from 
which creative startup groups from the community can exhibit themselves and their skills to the wider community. Since the display booths were designed in part to be portable, they can be reused over and again in other events, functioning as a sustainable mode of promotion.

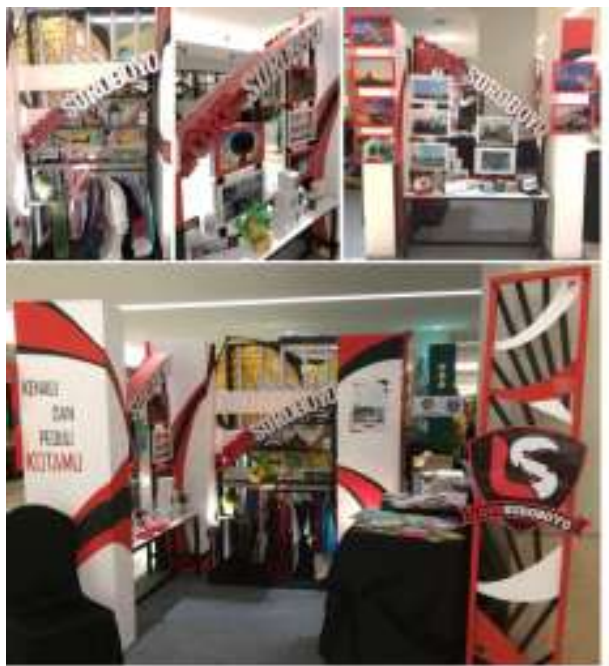

(a)

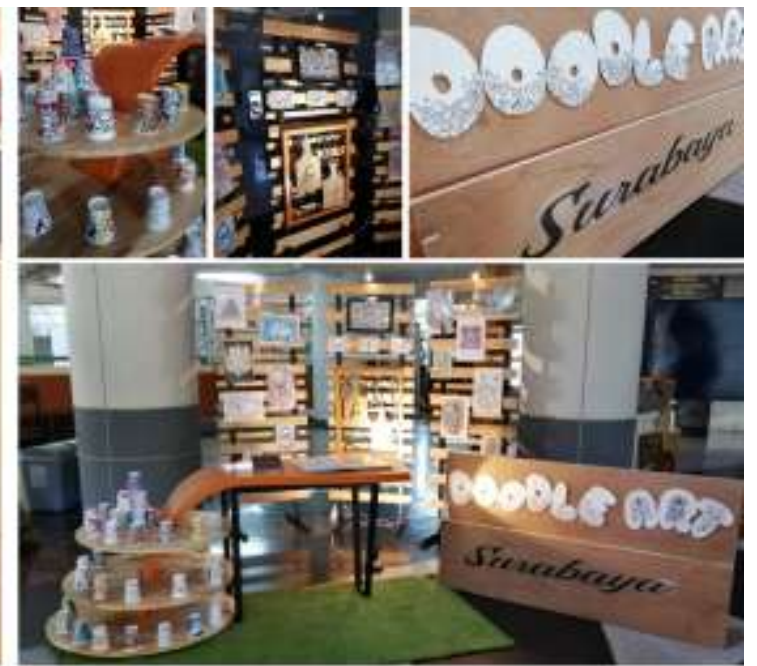

(b)

Figure 6. Results of exhibition facilities for the (a) Love Suroboyo Community, (b) Doodle Art Surabaya Community, constructed through the participatory and co-design process. The booth can grant opportunities for startup groups to display their skills to the public (Source: Author, 2019).

To ensure the effectiveness of the design prototypes yielded, the two teams performed usability tests in the Test stage of the design process by becoming lead-users along with the community in a public exhibition event for three days (Figure 7). The designers used the exhibition facility, performing the activities that users would normally do such as displaying, storing, changing or reaching for items, moving, dissembling and transporting. Meanwhile, the community supported the collaboration by posting the events on their social media platforms and being present to explain their works to visitors. By implementing the lead-user approach of human-centered design, the designers and community were able to evaluate the effectiveness of the design through self and user evaluation. They were able to evaluate whether their design product was feasible in terms of dimension, durability, and feasibility.

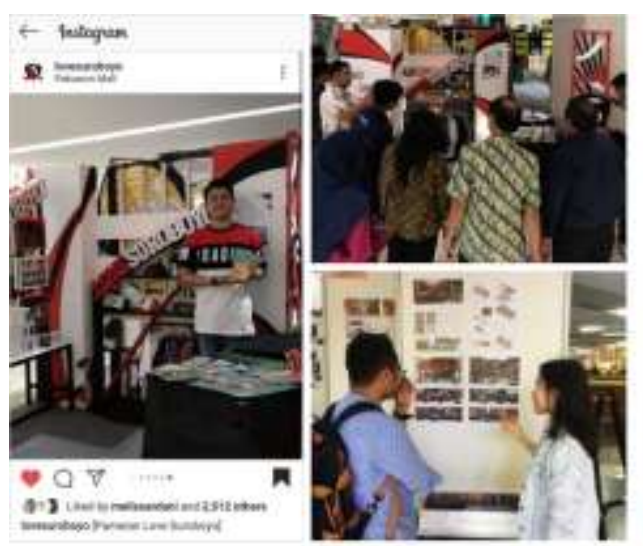

(a)
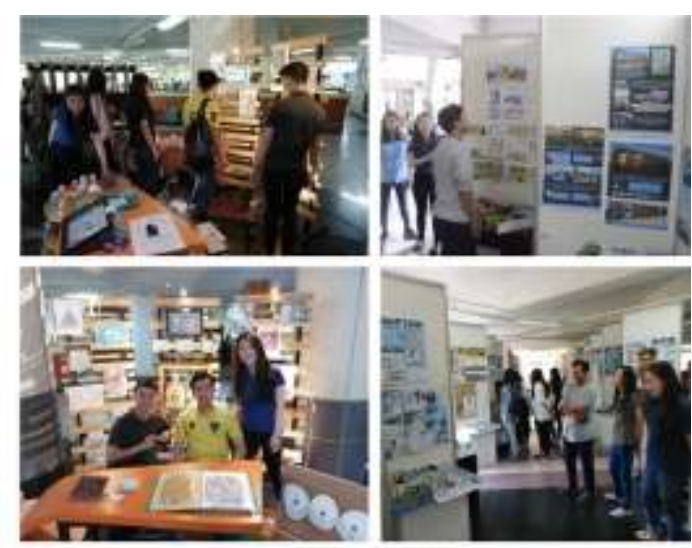

(b) 
Figure 7. Usability test with designers as lead-users followed by design evaluation process with end-users: (a) Love Suroboyo Community and (b) Doodle Art Surabaya Community (Source: Author, 2019).

Hence, the designers do not terminate their assistance before the usability test was performed to ensure that their impact strategy to empower the community through their design has been achieved (Bijl-Brouwer et. al., 2007). From the usability tests conducted, it was found that the design had enabled an effective and efficient way of displaying the different works of the communities, as they were designed according to the dimensions of the artworks, having contrasting colors and materials to the artworks to ensure their visibility. They were also effective for reuse in future events. They were also viable in attracting visitors and supported more purchases of their works compared to previous exhibition events. From the event and exhibition facility produced, as well as the subsequent active promotion from their social media account, the photography community had succeeded in increasing the public's interest in Surabaya photography. This could be seen from the increase of public response on the community's social media feed by $12 \%$ from before and after the event's use of the exhibition facility.

\section{Conclusion}

As recent studies in Indonesia have revealed the positive influence young creative communities have on the creative economy, architects and interior designers play a vital role in ensuring that the activities, works, and aspirations of these communities can increasingly be developed through creative designs of community spaces. Hence the design process of these spaces requires a truly human-centered approach to be able to cater to the unique character and needs of these creative communities. The benefits of a human-centered design approach have been proven through the design process conducted in this research-design project. In the Empathize and Point of View stages of the design process, the approach of empathy mapping and ethnographic field studies has enabled a deeper understanding of the users and their creative aspirations. The participation of designers in the community activities encouraged deep insights into the community's passion, the purpose of their existence, and their strong desire to convey their artistic expressions of freedom and creativity. This process had a major influence on the setting of design goals in the Define stage.

Because of the deep perception gained from the ethnographic field studies, the designers were able to set goals based on the context of the community's activities, character, and talents that could contribute to Surabaya's creative economy. In the Ideate and Prototype stages, the participatory and collaborative design approaches enabled a direct involvement of the community as users and experts in the design process, hence yielding novel design concepts and products that truly accommodate their unique activities and promote their values to the society, in contrast to previous conventional leased spaces that appear unappealing as they do not reflect the community's unique aspirations and characteristics.

From the interior space to the furniture details, the designs produced from the human-centered design process were truly customized for specific activities that could not have been produced through conventional designer-based design methods. Finally, the lead-user approach in testing the final product has enabled the designers to truly evaluate the effectiveness of their design in terms of social and economic functions. In this research, the movable exhibition booth design yielded from the human-centered design process has assisted the community in promoting their creative activities to the public, encourage the purchase of their artworks and collections and created meeting points for startup groups to develop their business units. This would facilitate new business units in the field of creative industries to grow and enhance the city's creative economy.

Hence, through human-centered design, creative communities could be empowered according to their unique characteristics. The approach can bring out a creative community's distinctive human values and resource through the design of creative community spaces and exhibition facilities that can also function as ignition points for startups in the field of creative industries and objects of economic and touristic 
development. Through human-centered design, building designers and educators could also be given more opportunities to become direct agents of social and economic improvements in the contemporary society.

\section{Acknowledgments}

This research was funded by the Indonesian Ministry of Research, Technology and Higher Education (PTUPT-DIKTI). The authors would like to acknowledge the collaboration with Love Suroboyo and Doodle Art Surabaya Communities as well as the efforts from the design team (Angga Jesslyn, Favian Grady, Melissa Ardani, Ellysa Halim, Elvina Kurniawati, Lavenia Emilia, Kenny Ray, Erlina Kurnia, Yosudhara Naritan, Adi Kelvianto, Graciela, Crisientia, Yoshua Nico, Sidartha Suteja, Andika P., Jovian Halim, Evelyn Janesty, Pamela Wijaya and Stacey Young) who have made this research possible.

\section{References}

Aref, F. (2011). Sense of community and participation for tourism development. Life Science Journal, 8(1), 20-25. https://pdfs.semanticscholar.org/430e/e3b1fccbf1035ebeeb88b89dd4e65c2983be.pdf

Brem, A., Bilgram, V., \& Gutstein, A. (2018). Involving lead users in innovation: A structured summary of research on the lead user method. International Journal of Innovation and Technology Management, 15(03), 1850022. https://doi.org/10.1142/S0219877018500220

Van der Bijl-Brouwer, M., \& Dorst, K. (2017). Advancing the strategic impact of human-centred design. Design Studies, 53, 1-23. https://doi.org/10.1016/j.destud.2017.06.003

Dewi, P.R.S. (2016) Public Interest in the Existence of Creative Space, Proceedings of IPLBI Scientific Meeting (2934) Malang: National Institute of Technology. https://temuilmiah.iplbi.or.id/wp-content/uploads/2016/12/IPLBI2016-C029-034-Kettarikan-Publik-Tadap-Kampang-Creative-Space.pdf

Anheier, H. K., \& Isar, Y. R. (Eds.). (2010). Cultures and globalization: cultural expression, creativity and innovation. Sage.

https://books.google.com.pk/books?hl=en\&lr=\&id=v8WF71N5JdoC\&oi=fnd\&pg=PP2\&dq=Duxbury,+N+and+Murray, + C. $+(2010) .+$ Creative+spaces.+in+Y.R.+Isar+\%26+H.K.+Anheier+(Eds.),+Cultural+Expression, + Creativity, + and + Inn ovation.+The+Cultures+and+Globalization+Series,+\&ots=C8vBbYk_e_\&sig=2nZ2g6Rc9dKOGDRAGdP813POJzU\& redir_esc $=\mathrm{y} \# \mathrm{v}=$ onepage $\& \mathrm{q} \& \mathrm{f}=$ false

El Sayad, Z. M., Farghaly, T., \& Hamada, S. M. (2017). Integrating Human-Centered Design Methods In Early Design Stage: Using Interactive Architecture As A Tool. Journal Of Al-Azhar University Engineering Sector, 12(44), 947-960. 10.21608/AUEJ.2017.19180

Crossley, L. (2003). Building emotions in design. The Design Journal, 6(3), 35-45.

https://doi.org/10.2752/146069203789355264

Luma Institute. (2012). Innovating for people: Handbook of human-centered design methods. LUMA Institute, LLC. https://books.google.com.pk/books/about/Innovating_for_People.html?id=bLyCMAEACAAJ\&redir_esc=y

Kang, M., Choo, P., \& Watters, C. E. (2015). Design for experiencing: participatory design approach with multidisciplinary perspectives. Procedia-Social and Behavioral Sciences, 174, 830-833. https://www.researchgate.net/publication/277651650_Design_for_Experiencing_Participatory_Design_Approach_with _Multidisciplinary_Perspectives

Hidayat, A. R., \& Asmara, A. Y. (2017, June). Creative industry in supporting economy growth in Indonesia: Perspective of regional innovation system. In IOP Conference Series: Earth and Environmental Science (Vol. 70, No. 1, p. 012031). IOP Publishing. https://iopscience.iop.org/article/10.1088/1755-1315/70/1/012031/pdf

Marzaman, A. (2018). Creative Community In The Framework Of Empowerment And Capacity Building Of Society (Komunitas Kreatif Dalam Rangka Pemberdayaan Dan Peningkatan Kapasitas Masyarakat Desa). Gorontalo Development Review, 1(2), 48-61. http://www.jurnal.unigo.ac.id/index.php/gdrev/article/view/349

Maulana, H (2020). More than $96 \%$ of Indonesia's creative economy business is not yet a business entity, Retrieved from https://infografik.kontan.co.id/news/lebih-dari-96-bisnis-ekonomi-k Creative-indonesia-belum-berbadan-usaha

Mulas, V., Nedayvoda, A., \& Zaatari, G. (2017). Creative community spaces: spaces that are transforming cities into innovation hubs. World Bank. https://doi.org/10.1596/28329

Pelto, P. J. (2016). Applied ethnography: Guidelines for field research. Routledge. https://doi.org/10.4324/9781315434698 
Pena, W. M., \& Parshall, S. A. (2012). Problem seeking: An architectural programming primer. John Wiley \& Sons. https://books.google.com.pk/books?hl=en\&lr=\&id=irXetoJcGyYC\&oi=fnd\&pg=PT8\&dq=Pena, $+\mathrm{WM}+$ and + Parshal, $+\mathrm{S}$ $\mathrm{A}+(2012) .+$ Problem+Seeking:+An+Architectural+Programming+Premier+Fifth+Edition $.+N e w+J e r s e y:+J o h n+W i l e y+a$ nd+Sons+Inc.\&ots=Cn9FtZDjhS\&sig=ta39R8AbdjROU2yf0s_3QVQh_lc\&redir_esc=y\#v=onepage\&q\&f=false

Steen, M., Kuijt-Evers, L., \& Klok, J. (2007, July). Early user involvement in research and design projects-A review of methods and practices. In 23rd EGOS Colloquium (Vol. 5, No. 7, pp. 1-21). https://pdfs.semanticscholar.org/c439/a2b40447ea37e2d58ce55d91d3a849b24137.pdf

Tinarso, P., Supartiningsih, S., \& Hadi, H. (2018). Axiology of Cultural Egalitarian Values "Arek Suroboyo". Al-Ulum, 18 (2), 395-416. https://doi.org/10.30603/au.v18i2.554

Zamenopoulos, T., \& Alexiou, K. (2018). Co-design as collaborative research. Bristol University/AHRC Connected Communities Programme. http://oro.open.ac.uk/id/eprint/58301 